\title{
Neoclasicismo, romanticismo y noción de literatura nacional en la Nueva Granada. \\ Un estudio a partir de la prensa literaria de 1836 a $1860^{1}$
}

\author{
Ana María Agudelo OCHOA ${ }^{2}$ \\ Universidad de Antioquia
}

\begin{abstract}
RESUMEN
La prensa neogranadina es un escenario privilegiado donde coinciden los balances acerca del estado de las bellas letras con los discursos de carácter programático que dibujan los rumbos que ha de seguir la literatura verdaderamente nacional. Unos y otros se encuentran atravesados por concepciones estéticas neoclásicas y románticas, que fundamentan las diferentes posturas acerca del valor y función de las manifestaciones literarias en el contexto específico de la república en vías de conformación. En este artículo revisaremos cuáles son específicamente los elementos neoclásicos y románticos subyacentes en los discursos a propósito de la literatura nacional y la literatura suramericana, publicados en la prensa literaria durante el periodo que va de 1836 a 1860. Además, demostraremos el valor que se otorga a géneros narrativos debido a su capacidad para ocuparse de temas vernáculos que forman al público lector al proveerlo de un discurso identitario.
\end{abstract}

Palabras clave: ensayo, ensayo hispanoamericano, ensayo mexicano, teoría de los géneros, cultura, lectura.

1 Este artículo se deriva de la investigación "Formas históricas del intelectual colombiano. Una reconstrucción a partir de la prensa literaria (1850-1900)" ejecutado con recursos de la Convocatoria de proyectos de investigación de Ciencias Sociales, Humanidades y Artes 2012 financiada por el Comité para el Desarrollo de la Investigación (CODI) de la Universidad de Antioquia; se inscribe en el marco de la Estrategia de sostenibilidad para grupos de investigación CODI 2013-2014.

2 Doctora en literatura, Universidad de Barcelona; Magíster en literatura Colombiana, Universidad de Antioquia. Profesora en programas de pregrado y posgrado en la misma institución. Directora de la revista Estudios de Literatura Colombiana. Integrante del grupo de investigación Colombia: tradiciones de la palabra. Contacto: ana.agudelo@gmail.com 


\title{
Neoclassicism, Romanticism and the notion of National Literature in Nueva Granada. Study based on literary press from 1836 to 1860
}

\begin{abstract}
The literary press in New Granada is a sample of the considerations that were made on beaux arts and the programmatical discourse that depict truly national literature's ways. These are interwoven with esthetical neoclassic and romantic conceptions that support the different views on the value and purpose of literary manifestations in the context of a Republic still on the process of being established. The present study revises the neoclassic and romantic elements lying under national and South American literature discourses to be found in the literary press from 1836 to 1860 . We also attempt to demonstrate the importance that is given to narrative genres because of their vernacular contents that educate the reader by giving him a discourse of identity.
\end{abstract}

Key words: Periodic publication, $19^{\text {th }}$ century Colombian literature, Neoclassicism, Romanticism, National literature.

SUMARIO: 1.Introducción. 2.Una discusión europea en tierras neogranadinas. 3. Los primeros textos programáticos. 4.La literatura nacional: ¿entre el neoclasicismo y el romanticismo? A manera de conclusión.

\section{Introducción}

La prensa puesta en circulación en la Nueva Granada, ${ }^{3}$ además de las cuestiones políticas, religiosas y comerciales, se ocupó de asuntos literarios, de allí que no sea extraño ubicar entre las páginas de periódicos de la época textos de creación y reflexiones acerca de la literatura y su lugar en el nuevo orden nacional, más comúnmente los primeros que los segundos. Pero son precisamente los textos de reflexión los que interesan para el caso de este estudio, en tanto fueron escenario de las ideas que circulaban acerca del estado de las letras neogranadinas y de los argumentos que defendían un carácter específico para el fondo literario nacional. ${ }^{4}$

${ }^{3}$ Nombre de Colombia entre 1830 y 1858, en clara alusión a la denominación del Virreinato. Se utilizará esta denominación a lo largo del artículo.

${ }^{4}$ El periodo que revisamos en este estudio coincide con la etapa de conformación de los partidos políticos tradicionales colombianos, liberal y el conservador, y con la fase de preponderancia del programa político liberal, que defiende, entre otras libertades, la de imprenta, hecho que redunda en la proliferación de periódicos de diverso carácter. De entre la gran cantidad de publicaciones periódicas aparecidas entre 1830 y 1860, seleccionamos aquellas que se ocuparon en alguna medida de asuntos literarios; la revisión de estas publicaciones permitió detectar 17 artículos periodísticos que reflexionan sobre la literatura, textos que vieron la luz en 12 publicaciones periódicas: La Estrella Nacional, El Argos, El 
La preocupación por los rumbos de las letras nacionales encuentra su explicación en el contexto pos-independentista de conformación de los estados nacionales en Hispanoamérica, cuando se otorga un estatuto particular a la literatura. La expresión de estas disertaciones en la prensa se comprende al revisar la importancia de estos medios en ese mismo contexto que acabamos de señalar, cuando se inicia a través de ellos la formación de la opinión pública y de un público lector, y aparecen grupos que emprenden cruzadas a favor del desarrollo cultural (Melo, 2008). A ello debe sumarse la relativa facilidad que conlleva su publicación, si se compara con las implicaciones que para ese entonces entraña la edición de un libro.

\section{Una discusión europea en tierras neogranadinas}

"Novísima escuela", (s.d., 1848: 2), "moderna escuela" (s.d., 1849a: 8), "escuela de Byron" (s.d., 1849c: 3) son algunas de las expresiones para nombrar la vertiente literaria que está tomando fuerza en el país y que se aleja de la preceptiva neoclásica. ${ }^{6}$ En el orden de ideas neoclásico —e ilustrado- la literatura está al servicio de la expresión de unos ideales; cualquier manifestación que ensombrezca el sentido, que impida la fácil comprensión del mensaje, es rechazada (Viñas, 2002: 202). Finalizando el siglo XVIII y a inicios del XIX comienza a emerger en Europa el espíritu romántico - toda una cosmovisión, una concepción de la vida - y con este se inicia el declive del neoclasicismo. La defensa de la libertad en la base del credo romántico se extiende también a la creación literaria: la norma neoclásica es puesta en cuestión (Viñas, 2002: 268).

Albor literario. Periódico científico, literario y noticioso, El Cachifo. Periódico literario, El Neogranadino, El Museo, Ensayo Literario, La Bagatela, La Reforma. Periódico de la escuela republicana, El Tiempo, Biblioteca de Señoritas y El Mosaico. Tienen en común estas publicaciones, además de los aspectos ya mencionados, ser publicadas en Bogotá —la capital del país-, ser iniciativas privadas y haber circulado, en la mayoría de los casos, durante pocos años. De este conjunto de publicaciones, podemos afirmar, además, que hacen parte del corpus que constituye los antecedentes del periodismo literario colombiano.

5 Buen número de los artículos periodísticos estudiados en este artículo fueron publicados sin dato de autor, práctica común en el siglo XIX en Colombia, como también lo fue el uso de seudónimos. En lo posible hemos tratado de establecer la autoría de los artículos, sin embargo en algunos casos fue imposible. Así, acudimos a la convención s.d. para indicarlo.

${ }^{6}$ A lo largo de los dos siglos y medio de imperio clasicista en Europa, el conjunto de ideas acerca de la literatura se mantiene prácticamente estable; en el clasicismo renacentista se da una aproximación a la creación literaria en términos prescriptivos, se enaltece la poesía en tanto género y al poeta como su cultor, se ve en la imitación una conducta adecuada en tanto se logre una síntesis de los modelos que sirven como fuente de imitación, se exalta el uso de las lenguas vernáculas, se emprende un culto a la dificultad poética (Viñas, 2002: 141-179). 
El siglo XIX se inaugura en Hispanoamérica bajo el "imperio" del estilo neoclásico, que se caracteriza por ser reflexivo, solemne y riguroso en el seguimiento de una prescriptiva; con una estricta idea del bien y del mal, de raíces laicas, y medio de expresión del interés por el progreso y el bienestar de la sociedad (Oviedo, 2012: 316). El espíritu romántico arriba a tierras hispanoamericanas ligado a los movimientos de emancipación política (Oviedo, 2012: 337); la tensión clasicismo/romanticismo, emprendida en Europa, se actualiza en tierras neogranadinas debido a las circunstancias específicas del sistema literario del país y tiene por escenario las publicaciones periódicas. Entre las principales expresiones de la vigencia que cobra la disputa antiguos/modernos en la Nueva Granada se cuentan los artículos donde se critica el carácter de las imitaciones de autores foráneos y la reproducción de textos reflexivos de autores extranjeros, algunos traducidos.

Buena parte de los artículos revisados coincide al arremeter en contra de la adopción de los "vicios" de la escuela romántica por parte de los jóvenes escritores. Las críticas en general apuntan a los problemas que conlleva la mala imitación, o la errónea interpretación, de modelos extranjeros; se ataca la reiterada inclinación por temas propios de las vertientes sentimental y gótica del romanticismo, en tanto resultan artificiosos y alejados de la realidad sociopolítica que se vive en el momento, cuyo marco no es otro que el de la independencia política recientemente lograda y sus consiguientes cuestionamientos relativos a la identidad nacional. No es gratuito entonces que los editores de La Estrella Nacional —hasta ahora considerado el primer periódico literario del país - abran su número 1 con el artículo "Novelas" (1836), cuyo autor se burla directamente de los epígonos de los precursores del romanticismo francés: "Estos son los grandes modelos que tratan de imitar nuestros jóvenes; i he visto mas de dos imitaciones, que harían llorar de la risa á cualquiera que tenga los cascos bien sentados" (s.d., 1836: 1). ${ }^{7}$ Diez años después, José María Rojas Garrido insiste en que se ha comprendido mal el romanticismo y señala la proliferación de un romanticismo, "ignorante", "bandolero", "criminal", al tiempo que critica que "Se deja de estudiar para ser romántico y se insulta la moral para no ser clásico" (Rojas, 1846: p. 4).

Los editores de El Cachifo - una publicación mantenida por jóvenes estudiantes del Colegio del Espíritu Santo- publican en 1848 el artículo "Bellas letras", exaltación de la norma neoclásica y una crítica a la adopción de un erróneo romanticismo que delata la ignorancia, desconocimiento de la lengua y de las normas de composición poética: "triste i desgraciada es a la verdad la condición de la literatura de un país, en donde los representantes de aquella, abrogándose derechos i facultades que no les pertenecen [...] rompen los estatutos literarios, despedazan el código de la sana crítica, forjando a su placer i satisfacción leyes i

\footnotetext{
${ }^{7}$ En esta y las demás citas textuales se conserva la ortografía de las fuentes revisadas.
} 
licencias arbitrarias" (s.d., 1848: 2). Es de resaltar en este artículo la preocupación por el estado de atraso del país y por la mala imagen que de este se forjen en el exterior por cuenta de la empobrecida producción literaria: "se dirá que no conocemos la lengua en que escribimos" (s.d., 1848: 3). Se crítica a la producción romántica de los compatriotas sus "títulos extravagantes", "variar el metro a cada estrofa", "colocar en tropel esdrújulos inoportunos", "[el] tinte fantástico i misterios", "[la] pobre imitación" (s.d., 1848: 3).

Pero la crítica a la imitación de modelos románticos sobrepasa los terrenos literarios y se adentra en asuntos relativos al comportamiento de los individuos. José María Rojas Garrido reconoce el valor de la obra de románticos europeos, como es el caso de Zorrilla (1846: 4), pero critica ferozmente a los imitadores neogranadinos quienes "desfiguran atrevidamente las producciones de buenos literatos para vomitar disparates dándole a un bello pensamiento el barniz de un absurdo. Nada hay tan común en nuestros escritores como el plájio, y nadie critica el peor de los defectos en literatura, acaso porque se teme haber incurrido en el mismo robo" (1846: 4). Rojas no se limita a la crítica el remedo, pasa a denunciar el comportamiento de quienes se consideran "románticos"; este autor apela a una anécdota donde presenta a un joven romántico — “joven paquete, que según la palidez de su semblante, los ojos hinchados y la voz ronca había pasado la noche en vela" (1846: 4) - como un ladronzuelo que finalmente obtiene su castigo. El cierre del texto de Rojas es directo: "He aquí la escoria de la elocuencia y del lujo: el romántico que dice disparates y plájia, es intolerable; pero el romántico que además, es un cachaco vago que vive de trampas, es el cuerpo del delito que comete la policía cerrando los ojos ante las plagas de la sociedad" (1846: 6). ¿Será tan feroz la crítica porque se perfila un escritor que va contra todo proyecto civilizador, de formación de buenos ciudadanos? De un escritor como este no podría esperarse una obra digna de conformar el ideal de la literatura nacional. Lo anterior abre la posibilidad de considerar que además de acudir al establecimiento de un ideal de literatura nacional, nos encontramos ante una propuesta de un ideal de escritor como individuo modelo de ciudadano.

En abril de 1849 aparece en El Museo un interesante texto - "Llanto i melancolía" - que proponemos como una síntesis entre artículo crítico y artículo propositivo, donde comienza a delinearse un programa para la literatura nacional. ${ }^{8}$ "Llanto i melancolía" expone toda una crítica a los rumbos románticos que han seguido los escritores del país al sumergirse en una poesía recargada de melancolía y llanto que los ha llevado a descuidar temas de mayor pertinencia. Este artículo es muy posiblemente el primero donde se utiliza la expresión "literatura nacional" (s.d., 1849b: 5) y se vincula a temáticas como la naturaleza circundante y la historia

\footnotetext{
${ }^{8}$ Designamos textos programáticos a aquellos que defienden unos determinados rasgos y funciones para la literatura, en el marco de una ideología o tendencia estética.
} 
patria (s.d., 1849b: 6). La estrategia retórica consiste en la sucesión de cuestionamientos y en el énfasis en las carencias de las bellas letras del país, para luego pasar a plantear las bases de la literatura nacional, que seguirán reiterándose en los textos programáticos de posterior publicación:

i cuando esperábamos que [el joven escritor], colocado en medio de las escenas robustas i brillantes de nuestro suelo, herido por todos lados con la presencia de mis fenómenos admirables i sorprendente, rodeado de una naturaleza grandiosa [...] alzara su voz cadente i soberbia para cantar nuestro mundo i sus bellezas [...] lo vemos remedar las viejas armonías de otros cantores $[\ldots]$ ¿Cuáles son entre nosotros los esfuerzos que se hacen, no diré para resucitar, sino para crear un gusto propio nuestro, i un fondo de literatura también peculiar a nuestro país? [...] ¿cuál de nuestros jóvenes entusiastas ha sacudido el polvo de nuestras viejas memorias para desenterrar hechos gloriosos? ¿Cuál ha cantado nuestros héroes, cuál nuestra odiosa servidumbre, nuestra independencia, nuestras luchas, nuestra redención política? ¿Cuál ha celebrado la historia de este mundo grande i celebérrimo en vez de componer odas a la luna, que ya está cansada de oir tantas deprecaciones i tantos llorones nocturnos? (s.d., 1849b: 6).

Uno de los colaboradores de El Ensayo literario se lamenta del camino que han tomado los jóvenes escritores y propone un rumbo acertado para la literatura nacional. Su diagnóstico apunta, como los anteriores artículos citados, a criticar el "aire tan Byronesco" (T.G.U., 1849: 1) que han asumido los poetas; recurre, irónicamente, al uso excesivo de adjetivación y de giros románticos: "nada vale escribir si á cada renglon no hai una tumba al lado de una orgía $[. .$.$] aunque traten$ de alabar á una muchacha alegrona, al momento les viene al apurado cerebro, que sus narices parecen un lúgubre panteón, i sus ojos la revoltosa orgía con su voluptuosidad, i su alarma, i sus estentoreos gritos" (T.G.U., 1849: 1). El articulista, ante la necesidad de refrenar este tipo de excesos y encaminar las letras vernáculas, atrae la mirada hacia a la historia y territorio propios, en una invocación que indudablemente tiene ecos de la "Alocución a la poesía" de Andrés Bello. ${ }^{9}$ Dice el autor de artículo periodístico:

Emigren esos grandes genios, que el suelo yermo de la Europa no puede saciar sus fantasías [...] vengan , i el genio de la América les brindará la copa de los Profetas $[\ldots]$ nuestra literatura tiene muchas fuentes que agotar $[\ldots]$ nuestros

9 "Divina poesía,/ tú, de la soledad habitadora,/ a consultar tus cantos enseñada/ con el silencio de la selva umbría;/ tú, a quien la verde gruta/ fue morada,/ y el eco de los montes compañía;/ tiempo es que dejes ya la culta Europa,/ que tu nativa rustiquez desama,/ y dirijas el vuelo adonde te abre/ el mundo de Colón su grande escena. [...] Del Cotopaxi ve a extinguir la hoguera/ que ceban las entrañas de los Andes./ Mira correr la sangre de Rovira,/ a quien lamentan Mérida y Pamplona [...]" Bello (1993: 4). 
poetas pueden ir á recoger los llantos del Tequendama por nuestros siglos de opresión i nuestros sufrimientos [...] ellos pueden ir á saciar su oido con el sordo bramido del Cotopaxi, predicando la libertad; á contemplar con embeleso nuestros campos i descansar en paz; emigrar al Sur, al Cabo de Hornos; ó detenerse en el Mar de Colón (T.G.U., 1849: 2).

En el artículo "Literatura nacional", publicado en La Reforma en 1851, después de algunas disquisiciones a propósito del sentido de las normas y las leyes en literatura - donde se defiende que primero hubo literatura y luego leyes que la rigen, que estas leyes son mutables, que seguir las leyes no garantiza creación de buen gusto (s.d., 1851: s.p.) — , el autor niega la existencia de una literatura nacional, bajo el siguiente argumento: "En la literatura de un país cuando le es peculiar i privativa, cuando es esencialmente nacional, encontramos el zumo de la civilización, los rasgos característicos de sus costumbres, de su jenio i aun de su gobierno. Cuando no es tal, solo hallamos en la literatura de que se cree poseedor, un remedo mas o ménos ridículo, mas o ménos bastardo de la literatura de otra nación" (s.d., 1851: s.p.). A continuación el autor reflexiona sobre la imitación y señala como la literatura del país es remedo de la Española, que a su vez lo es de la Francesa. Un doble remedo de baja calidad (s.d., 1851: s.p.).

A las reflexiones que acabamos de pasar revista subyace el temor por el desprecio que genera la norma neoclásica, desprecio que según los articulistas oculta un desconocimiento de la lengua y en este sentido un desprecio por el conocimiento. Llama la atención que pese a las continuas críticas, la mayoría dirigidas a los jóvenes talentos, no se personalice ninguna de las afirmaciones, es decir, no se señalen obras o autores concretos. Así, son críticas de tinte generalizador. No obstante sí es común que se mencionen autores románticos extranjeros cuya obra se valora positivamente, caso de Lamartine, Madrazo — no es claro si Luis o Federico- y Salvador Bermúdez. La imitación de modelos románticos europeos - franceses y españoles en mayor medida, e ingleses y alemanes a menor escala - es común en las naciones hispanoamericanas a lo largo del siglo XIX; después de la independencia, España deja de ejercer como filtro de la bibliografía que llega a América, así circulan más fácilmente obras de autores de otros países europeos (Carilla, 1967: 48). En el caso específico de la Nueva Granada también se vive el afrancesamiento de cierto sector de la sociedad, y con ello el aumento del interés por autores galos; no obstante, en el país el nexo con autores españoles continúa siendo cercano, a diferencia de otros países que intentaron romper con mayor fuerza con su antecedente español (Carilla, 1967: 5997). ${ }^{10}$ Aunque los románticos ingleses tuvieron menor difusión en Hispanoamérica,

${ }^{10}$ En "Novelas" (1836) el autor comenta principalmente novelas y autores franceses, pues están a la moda en ese entonces, pero se permite algunas palabras sobre las novelas españolas, de las cuales afirma: "valen literaria y moralmente mas que todas las novelas de las señoras francesas" (s.d., 1836: 2). 
Colombia es un caso especial dada la singular acogida que tuvieron autores de esta región. ${ }^{11}$ De allí la continua alusión a Byron en los artículos revisados y la utilización de adjetivos como "byroniano" para describir un cierto tipo de imitación (Carilla, 1967: 83).

Los hábitos lectores de los neogranadinos ofrecen pistas acerca de las obras que están circulando en el país y permitirían deducir posibles fuentes de influencia para los escritores. El texto "Novelas" (1836) informa de la circulación y lectura de obras francesas precursoras del romanticismo: Rousseau (Nueva Eloisa), PigaultLebrun, Louvet de Couvray (Aventuras del caballerito Foblás), Sophie Cottin (Matilde o las cruzadas), madame de Genlis, Jacques-Henri Bernardin de SaintPierre (Pablo y Virginia), Chateaubriand (Atala). Asimismo ofrece pistas sobra la circulación de autores de cepa británica como Ann Radcliff, Walter Scott y Oliver Goldsmith (s.d., 1936: 1-2).

Pese a que las literaturas francesa e inglesa ejercen influencia en los discursos sobre la literatura, detectamos una relación interesante con el antecedente hispánico. Los artículos revisados dan cuenta de que autores españoles son leídos, imitados y comentados -Zorrilla, Gil y Zárate, Donoso Cortés, Lope de Vega, Saavedra, Martínez de la Rosa - además, como queda claro en los textos de Felipe Pérez y José Caicedo Rojas, se reconoce la ligazón de la literatura vernácula con la peninsular. La cercanía que mantienen la Nueva Granada, Perú y México con su antecedente hispánico - o más bien el hecho que no se distancien de manera tan categórica como Argentina- ${ }^{12}$ encuentra una posible explicación en la riqueza de su literatura colonial, fenómeno que fortalece los lazos con el excolonizador (Carilla, 1967: 44).

Las posturas diversas en cuanto a la disputa neoclasicismo/romanticismo se evidencian no solo en artículos que critican la imitación y revisan hábitos lectores, también se revelan en textos escritos por autores extranjeros y reproducidos en los periódicos nacionales. Podríamos afirmar que de manera simultánea se estaban publicando escritos a favor de una y otra escuela. En 1846 José María Rojas Garrido publica en El Albor literario un artículo que abre de la siguiente manera: "Hace muchos años que la cuestión románticos y clásicos se suscitó entre los literatos españoles; nosotros hemos formado parte del mudo auditorio que no tiene voto" (Rojas, 1846: 3, subrayado en el texto original). Estas palabras ponen en evidencia la vigencia de la polémica en suelo neogranadino; la supuesta nula participación en la misma, denunciada por Rojas, tendría que matizarse en tanto es posible encontrar entre las páginas de algunas publicaciones periódicas

11 Tal cercanía tiene explicaciones de carácter comercial (Carilla, 1967: 81).

${ }^{12}$ Dávila (2003) presenta el caso de Chile con Lastarria, quien en su programa para la literatura nacional señala la necesidad de cortar de raíz con la tradición española" (64). Una manifestación tan tajante como esta no la hemos ubicado en los periódicos estudiados. 
reproducciones de fragmentos de obras de autores como Madame Stäel, Juan Donoso Cortés, Antonio Gil de Zárate y Nicolás Boileau, que configurarían en principio la formación en la materia del público lector y sentarían bases para la discusión. En ese contexto fue ineludible apelar a modelos externos para construir la propia idea de nación y configurar un ideal de literatura nacional. La difusión de las obras de estos autores europeos es termómetro de la influencia de ideas románticas y neoclásicas en el ámbito neogranadino, asimismo es índice de la necesidad por retomar la polémica clasicismo/romanticismo. La divulgación en tierras neogranadinas de reflexiones a propósito de la literatura emanadas en otros sistemas literarios -en nuestro caso concreto el español y el francés - se comprende como parte de las dinámicas de la conformación del repertorio propio de una literatura nacional en vías de fundación; ${ }^{13}$ la traducción es una de las estrategias para adoptar elementos de otros repertorios, estas estrategias cobran importancia en tanto permiten la adopción de diversos modelos estéticos a un sistema literario específico (Even-Zohar, 2011b: 90). Siguiendo la lógica de Even-Zohar (2011a: 43), podemos afirmar que el naciente sistema literario neogranadino, cuyo repertorio propio es limitado por ser un sistema joven, se encuentra más dispuesto a explotar otros sistemas disponibles, en este caso útiles al programa literario en proceso de estructuración.

En diciembre de 1838 el periódico bogotano El Argos publica una traducción de un texto de Madame Stäel bajo el título "Influjo de la literatura sobre la libertad". En términos generales, Stäel sostiene que la existencia de la nación libre se sostiene sobre las bases del conocimiento, así, el ciudadano ha de ser ilustrado; tarea de los escritores es difundir este conocimiento. El sentido que Stäel le otorga a la palabra literatura es de carácter amplio en tanto denota el conocimiento en general, no sólo las bellas letras. Tan solo dos años antes, el autor de "Novelas" (1836) reconocía los méritos de la escritora romántica pero no recomendaba su lectura. Claramente, la obra de la escritora suiza resonaba entre quienes reflexionaban acerca de la literatura en ese entonces. El artículo de El Argos es la traducción de uno de los capítulos de De la littérature considérée dans ses rapports avec les institutions sociales (1800), el título del capítulo es: "De la littérature dans ses rapports avec la liberté" (Stäel, 1800: 23-27). ${ }^{14}$ Esta traducción viene acompañada de un párrafo final donde los editores invitan a los jóvenes neogranadinos a que cultiven su

${ }^{13}$ Repertorio entendido en términos de Even-Zohar como "el conocimiento compartido necesario tanto para producir (y entender) un texto, como para producir (y entender) varios otros productos del sistema literario" (2011a: 42).

${ }^{14}$ En el periódico neogranadino no se informa de dónde fue tomada la traducción ni quién es el traductor. Cabe anotar que la traducción omite cuatro párrafos y medio de la versión original (el texto original consta de once párrafos, mientras que la traducción incluye seis y medio). 
conocimiento; se les convoca como generación que está en proceso de formación para suceder a la primera generación republicana. Pese a que no se resalta el sentido de más peso del texto traducido (todas las reflexiones a propósito de la libertad, por ejemplo), es significativo que la traducción circule en un periódico de la época pues sirve de acicate para la construcción de una identidad nacional: "La elocuencia, el amor de las letras i de las bellas artes, en una palabra, la filosofía, pueden solo hacer de un territorio una patria, dando á la nación que lo habita los mismos gustos, los mismo hábitos, i los mismos sentimientos" (Stäel, 1838: 238). Las interesantes ideas de Stäel a propósito de la novela y su función social, contenidas en otros trabajos de la autora, no se reflejan en el citado texto, pero podemos aventurar que demás trabajos de la autora fueron conocidos por los letrados neogranadinos. ${ }^{15} \mathrm{En}$ este punto es importante señalar la importancia que jugaron ciertos espacios de sociabilidad como mediadores culturales para el caso de concreto de la corriente romántica europea en América. Precisamente el salón de madame Staël y su obra hicieron posible que hispanoamericanos como Bolívar y Miranda se familiarizaran con el romanticismo alemán (Krumpel, 2001: 47-48).

En "Una noche romántica y un día clásico" Rojas Garrido cita las palabras del escritor español Juan Donoso Cortés, a propósito de las escuelas clásica y romántica (1846: 4). El texto de Cortés se titula "El clasicismo y el romanticismo"; ${ }^{16}$ su autor, más allá de intentar una defensa de uno u otro modelo, estudia en profundidad ambos fenómenos. Mediante una revisión de carácter histórico, explica su razón de ser y asocia la escuela clásica a la literatura antigua y el romanticismo a la literatura moderna. Concluye que ambos son válidos. Rojas Garrido se vale de fragmentos descontextualizados de la obra de Cortés para descalificar ciertas manifestaciones de romanticismo, y en este sentido corrompe la esencia de su fuente.

En julio de 1849 aparece entre las páginas de El Museo un fragmento del Manual de literatura (1842-1844) de Antonio Gil de Zárate, el fragmento en cuestión corresponde al capítulo II de la Sección tercera del libro y se titula "Diferencias esenciales entre la literatura antigua y la moderna". ${ }^{17}$ Los editores de El Museo sustentan la publicación del fragmento en la actualidad de la polémica "literatura antigua" y "literatura moderna", no obstante no sientan una postura al respecto. Cabe anotar que la obra de Gil es citada a pocos años de su publicación en España. El mismo Gil de Zárate señala la validez de una y otra postura, si bien defiende la necesidad de leyes que rijan las obras emanadas de una y otra propuesta;

15 Según Carilla (1967: 77), en Hispanoamérica circularon novelas de Stäel (Corinne, Delphine), pero el prestigio de la escritora suiza en estas latitudes tuvo más que ver con la recepción de su obra De l'Allemagne.

${ }^{16}$ El escrito tiene una extensión de 36 página, al parecer circuló en prensa inicialmente. Fue recogido posteriormente en la obra Obras completas (Donoso Cortés, 1854).

${ }^{17}$ Ver Gil y Zárate (1861). 
él mismo transitó en su obra literaria - principalmente en su teatro- del neoclasicismo al romanticismo. Gil de Zárate caracteriza uno y otro "sistema", una y otra literatura: "los antiguos veían lo ideal de la naturaleza humana en la feliz proporción de sus facultades, i en su armónica concordancia; los modernos, al contrario, tienen el sentimiento profundo de una desunión interior, de una doble naturaleza del hombre, que hace de aquel ideal imposible de realización" (Gil de Zárate, 1849: 70).

Resulta curioso que la preceptiva neoclásica por excelencia, la poética de Nicolás Boileau, aparezca en prensa neogranadina años después de los textos citados anteriormente. La obra del francés aparece en La Bagatela a partir de su número 2 (septiembre de 1852) en la traducción de José María Salazar. Boileau es considerado el principal teórico del clasicismo, con su Art poétique (1674). Este neoclásico defiende firmemente la importancia de seguir la normativa poética en tanto esta es dictada por la razón, por el sentido común, pues el buen gusto es un principio universal (Viñas, 2002: 184). La obra de Boileau resume una suerte de credo neoclásico que se concreta en las siguientes ideas: el talento natural y disciplina se conjugan en la creación, se enaltece la razón, se asocia a la obra literaria una utilidad moral, además destacan las ideas de mímesis, decoro y verosimilitud (Viñas, 2002: 183-198). La preceptiva de Boileau aparece en 1674 y la traducción de Salazar data de 1810, aunque entra en circulación en 1828. La reproducción de la versión de Salazar en La Bagatela da cuenta de la vigencia de la preceptiva neoclásica cuarenta años después de su primera traducción en territorio neogranadino (en ese entonces aún virreinato). La traducción se publica en $L a$ Bagatela bajo el título "Poesía" y viene introducida por un par de párrafos, posiblemente escritos por alguno de los editores del periódico; este apartado introductorio resalta la importancia de las reglas para la composición poética, a la vez que señala el desconocimiento de la normativa por parte de los ingenios neogranadinos (Boileau, 1852: s.p.). Aunque existen otras traducciones al castellano de la poética del neoclásico francés, los editores de La Bagatela optan por publicar la versión del compatriota Salazar, posiblemente tratando de legitimar ante los escritores a quienes va dirigido el texto la legitimidad de la influencia de Boileau y de la vigencia de la escuela neoclásica, donde la poesía debe tener por objeto "deleitar i amonestar o corregir" (introducción a Boileau, 1852: s.p.). Claramente con esta publicación La Bagatela asume una postura de defensa del modelo neoclásico, pese a que la publicación de obras de otros autores europeos en periódicos neogranadinos ha ofrecido otros matices y posibilidades frente al romanticismo.

En todo caso, las publicaciones periódicas sirvieron como vehículo de divulgación de libros, de fragmentos más específicamente, que exponían importantes discursos a propósito de la literatura. La obra de Stäel apunta más a un sentido amplio de literatura "arte de pensar i de explicar los pensamientos" (1838: 237); los textos de Boileau, Gil de Zárate y Donoso Cortés sí evidencian un interés 
más específico en la producción literaria, entendida en un sentido más restringido. La disputa entre "antiguos y modernos", una vieja disputa europea, se actualiza en tierras americanas como parte del proceso de formación del programa para la literatura nacional.

Estos artículos, que aparecen entre 1836 y 1852, exponen aspectos fundamentales tanto del romanticismo como del neoclasicismo, comprenden argumentaciones más sólidas y elaboradas que las presentes en los artículos de autores neogranadinos. A partir de la década de los años cincuenta los textos de autores nacionales se complejizan y presentan posturas más cimentadas que defienden la necesidad de una literatura nacional.

\section{Los primeros textos programáticos}

Las denuncias y críticas provocadas por el estado de las letras — por su inclinación al romanticismo "Byronesco"- se entremezclan con las propuestas a favor del establecimiento de un fondo literario nacional, de allí que buena parte de los artículos lleven títulos del tipo "literatura nacional", "literatura suramericana", "nuestra literatura". En el artículo "Literatura nacional" publicado en La Reforma en 1851, el articulista tiene clara la diferencia entre las dos caras de la misma moneda: la literatura que efectivamente se está escribiendo y la literatura que se debería escribir (s.d., 1851: s.p.); es verdaderamente nacional la literatura "de un país cuando le es peculiar i privativa, cuando es esencialmente nacional, encontramos el zumo de la civilización, los rasgos característicos de sus costumbres, de su jenio i aun de su gobierno" (s.d., 1851: s.p.).

Resulta muy interesante que estos textos de carácter programático en general se inclinen por los géneros narrativos, especialmente por la novela: "La novela, con más recursos y menos dificultades que el poema, es hoy la verdadera rama épica de la literatura" (Pérez, 1858c: 85). Asimismo estos textos programáticos ofrecen recomendaciones acerca de los temas adecuados para un fondo literario nacional. "Novelas" (1836) es el primer artículo que hemos ubicado donde se comienza a establecer la obra de Walter Scott como modelo digno de imitación. Así, ya desde la década de los años 30 se emprende la tarea de sentar las bases de un ideal de literatura nacional por la vía de la novela histórica. De esta manera, una forma apreciada por los románticos comienza a perfilarse como la ideal para expresar los ideales nacionalistas, bajo criterios cercanos al neoclasicismo. El autor del artículo ve en la obra de Walter Scott una vertiente adecuada de la novela: "la risa, el llanto, lo patético i lo ridículo van unidos como lo van en las sociedades humanas. No hai duda que esta clase de novelas es instructivas" (s.d. 1836: 2). Además, para el caso de las lectoras se sostiene que las novelas de Scott les allana el camino hacia el conocimiento de la historia, el cual posiblemente no podrían adquirir mediante los libros especializados en la materia (s.d., 1836: 2). Los argumentos para juzgar la novelística de Scott asimismo se basan en preceptos neoclásicos: cercanía a la razón, a la verdad, carácter educativo de las obras. Esto es, educar deleitando. 
Como lo mencionamos en el apartado anterior, artículos aparecidos en 1849 como "Nuestra literatura", publicado en El Ensayo literario, y "Llanto i melancolía", publicado en El Museo, dan las primeras puntadas de un programa para la literatura nacional; básicamente proponen temas que deberían ser cultivados por los poetas y que se resumen en: historia de la Colonia (época subyugación), Independencia (como periodo heroico) y la exuberancia, riqueza y particularidad del territorio nacional.

Dos artículos publicados en El Neogranadino en 1849 — "Poesía americana" y "Poesía nacional" - proponen claras líneas programáticas para la literatura nacional: vinculación a un programa social; uso de temas y lenguajes populares; referencia a tradiciones, costumbres, territorio e historia - asuntos profundamente vitales y vigorosos, en oposición a los europeos-; cultivo del romance como género adecuado para el tratamiento de tales motivos. El concepto de "literatura nacional" comienza a vincularse a la "expresión de las necesidades sociales", "a los fines sociales i nacionales", al canto de "episodios de la guerra de Independencia, o las costumbres i tradiciones" (s.d., 1849c: 3). En este sentido, se propone también una función del poeta: "inspirado sacerdote de una civilización recién-nacida, llena de libertad i de porvenir" (s.d., 1849c: 3). Así, se presenta de manera mucho más clara y contundente el programa social literario: se equipara poesía descriptiva a poesía social "i por consiguiente original" (s.d., 1849d: 49); que no es otra que una literatura inspirada en la realidad circundante, en la propia historia y con una visión de progreso aunado a un proyecto civilizador. ${ }^{18}$ Un aspecto interesante de los artículos de El Neogranadino es su uso temprano de la expresión "tipos orijinales" (s.d., 1849d: 49) tan propia del costumbrismo; este par de textos no solo especifican los rasgos y géneros propios de una literatura nacional, también especifican los temas:

Materiales sobrados hallaría el poeta en las diversas costumbres que caracterizan nuestras provincias, desde los ardientes llanos de Casanare hasta los helados valles de los Andes, desde la movilidad de los habitantes de nuestras costas hasta la quietud taciturna del indio de las tierras altas, desde el vivir excepcional del boga del Magdalena, mitad salvaje, mitad civilizado, hombre de vigorosas pasiones, menospreciador de la delicadeza del blanco de las ciudades, fiel en su cariño, temible en su odio; hasta el vivir recojido y sentimental de nuestras damas, entregadas a los estravíos de una devoción exajerada para gastar en ella

18 Poesía - o literatura - social entendida en el programa del romanticismo social sansimoniano, que inspiró posturas político-sociales en letrados como Esteban Echeverría. Del romanticismo social los ideólogos hispanoamericanos retoman instrumentos para comprender y proyectar la realidad social de los pueblos, tales como el liberalismo económico y el industrialismo como caminos para acabar con la miseria (Zea, 1976: 74). 
las fuerzas de su espíritu i la vehemencia de una imaginación exaltada por la soledad misma i la monotonía de la existencia (s.d., 1849d: 49).

Estos textos publicados en El Neogranadino, al parecer obra de un mismo autor, son quizá los primeros en proponer modelos hispanoamericanos - no europeos- a los autores neogranadinos; la poesía gauchesca atrae la atención del articulista, quien señala la obra del argentino Hilario Ascasubi como paradigma del poeta americano, en tanto él ha comprendido sus deberes como poeta (s.d., 1849c: 3). Los comentarios a la obra de Ascasubi son retomados del periódico chileno Comercio de Valparaíso. En el artículo chileno, al igual que en la prensa neogranadina, se defiende una literatura que atienda "el modo de decir tan nuevo i tan vigoroso de los pueblos americanos, teniendo además el recurso de la originalidad de sus costumbres i de la novedad de los paisajes en que viven" (1849c: 3). El poeta debe descender: "hasta la inteligencia del pueblo" (1849c: 3). También se hace referencia a Bartolomé Hidalgo como cultivador de la poesía social. Uno de estos artículos viene acompañado del romance argentino "La severa", insistiendo con ello en el planteamiento de la poesía gauchesca como modelo digno de imitación. Cabe aclarar en este punto que la poesía gauchesca, al igual que el corrido mexicano, es una vertiente específica americana del romance español, cultivada por Hidalgo, Ascasubi, Lussich, Hernández (Carilla, 1967: 237).

"Literatura nacional" (El Tiempo 1855) abre señalando directamente el valor de la novela histórica, a la manera de Scott, Dumas y Bulwer (posiblemente Edward Bulwer-Lytton) (s.d., 1855: s.p.); valor que radica en su capacidad de enseñar por medio de la fábula (s.d., 1855: s.p.). Se diferencia entre el escritor fiel a la historia y aquel que "exajera y la pervierte" (s.d., 1855: s.p.). Se defiende, además, que los motivos propios de la novela histórica deben ser aquellas hazañas y hombres trascendentales (s.d., 1855: s.p.). Propone como temas: "Los pueblos primitivos de nuestras comarcas rodeadas de toda la orijinalidad de su historia i de su naturaleza, ofrecen al jenio americano ancho campo, todavía no cultivado. Aliando a la descripción de los países con la pintura de las costumbres i la inquisición de las civilizaciones del Nuevo Mundo" (s.d., 1855: s.p.). Temas de la Conquista y la Colonia se proponen como adecuados. Este es el primer artículo donde se revisa la obra de talentos nacionales, es decir, de escritores que se ajustan a la preceptiva que se empieza a delinear, sobre todo en lo concerniente a la novela histórica. Los autores aludidos son "el malogrado Anjel" (s.d., 1855: s.p.) [debe tratarse de José María Ángel Gaitán (1819-1851) autor de El doctor Temis], "la mano que delineó a Jilma" (s.d., 1855: s.p.) [debe tratarse de Felipe Pérez, autor de novelas históricas] y "el Sr. Eustacio Santamaría, autor de las 'Confidencias de un cura de mi pueblo"" (s.d., 1855: s.p.). El resto del artículo es un comentario a esta última obra, que en general es elogioso y revisa el manejo de la lengua, la construcción de los personajes, y resalta la "claridad i nitidez", la "sencillez sin desaliño" (s.d., 1855: s.p.). 
La Biblioteca de señoritas es la publicación que concentra mayor número de artículos de carácter programático, todos publicados en 1858. José Caicedo Rojas, bajo el seudónimo de Yarilpa, propone en el artículo "El romance" toda una defensa del género - como se hizo casi una década atrás en El Neogranadino - en tanto forma adecuada para materializar "nuestra incipiente literatura" (Caicedo, 1858: 46). Entre las bondades que Caicedo abona al género se cuentan su fácil composición, su facilidad para popularizar temas históricos nacionales, el que cuente con una prescriptiva, su cultivo por parte de escritores canónicos españoles (Lope de Vega, Saavedra, Martínez de la Rosa) (1858: 46). La invitación a seguir los modelos españoles se apega a consideraciones neoclásicas, en tanto Caicedo recomienda en la composición de romances seguir a estos autores y con ello contribuir a formar el gusto y corregir los vicios (1858: 46). El romance - forma de innegable raíz española y que revela el aprecio de la estética romántica por la poesía popular- fue, en efecto, un género cultivado por autores románticos hispanoamericanos. Del texto de Caicedo se deduce que esta forma está siendo cultivada en el país, sin embargo él no ofrece información sobre obras o autores. ${ }^{19}$

"Literatura suramericana" es el segundo de los artículos prescriptivos que hemos ubicado en la Biblioteca de señoritas. En este Felipe Pérez emprende una profunda reflexión acerca de la noción de literatura; revisa la acepción que vincula el valor de una literatura con el desarrollo de la lengua y del conocimiento en general ${ }^{20}$ asimismo revisa la perspectiva desde la cual bien puede hablarse de literatura para el caso de pueblos menos civilizados, con un desarrollo más pobre de su lengua; a partir de tales reflexiones se adhiere a quienes defienden la idea que la literatura suramericana es una "rama menor" de la española (Pérez, 1858a: 53-54), aunque no por ello de menor valor: "respecto de ese todo encantado e inestimable de la literatura de la raza española, no somos los suramericanos meros consumidores o usufructuarios, si así nos podemos espresar, sino verdadera i relativamente dignos i fecundos colaboradores" (Pérez, 1858a: 54). De los textos revisados, este de Pérez es el primero que defiende la ascendencia española de la tradición literaria nacional en ciernes. Pérez reconoce el cúmulo de motivos propios, pero se pregunta a la vez: “¿bastará eso para cambiar intrínsecamente la naturaleza del hombre i de las cosas? ¿Será eso suficiente para alterar nuestra literatura hasta hacerla distinta de la de nuestros padres, toda vez que conservamos

${ }^{19}$ Carilla (1967) señala que en Colombia cultivaron el romance José Manuel Marroquín, Rafael Pombo, Epifanio Mejía y José Eusebio Caro; asimismo afirma que este género poético que privilegia la narración fue propio de naciones cercanas a su herencia española, donde no se establece una ruptura vigorosa con la tradición ibérica (233-234).

${ }^{20} \mathrm{Si}$ bien el artículo no está firmado, es posible deducir de la publicación misma que el autor muy posiblemente sea Pérez, pues fue el editor y autor de las columnas que abren cada número en esta época de la Biblioteca. 
su religión i su lengua, su sangre i sus costumbres? No; i no debemos dejarnos sorprender por una apariencia fascinadora" (Pérez, 1858a: 54). Así, el concepto de "literatura nacional" en Pérez debe remitir obligatoriamente a la raíz española de la misma. En el artículo “¿Quién tiene la culpa?” Pérez continúa el texto anterior y estudia las razones tras el pobre de obras que canten las glorias pasadas y que cimentaron las bases de una nación libre. En suma su diagnóstico es falta de apoyo al escritor: "No es pues asunto el que nos falta: lo que nos falta es el apoyo social, el estímulo de los poderosos [...] ¿Quién tiene la culpa? La sociedad. Ella que, cuando mas, cree que ha hecho mucho por un hombre de injenio cuando lo aparta de la senda de flores de la poesía i lo lleva a empellones por la rápida política" (Pérez, 1858b: 62). Estas palabras de Pérez revelan cierta consciencia de la necesidad de profesionalización del escritor, cuya labor social a través de la literatura es necesaria, y se acercan a las del artículo "Poesía americana" de El Neogranadino, donde se propone al poeta como sacerdote de la civilización.

En "De la novela", Pérez se vale de sus artículos anteriores para apuntalar su propuesta personal acerca de la novela como género por excelencia para establecer un fondo literario nacional: "la novela, esa forma del pensamiento perfecto, es la única que puede hoy resumirlo todo, poesía, doctrina e instrucción" (Pérez, 1858c: 86). Este letrado entiende el género novelístico como posibilidad de síntesis entre historia, costumbres y doctrina, con un gran potencial ante el público lector: "[la novela] penetra en todos los hogares desde el palacio hasta la cabaña, i penetra para triunfar en el corazón de todos los sexos, sean cuales fueren su edad i sus condiciones" (Pérez, 1858c: 86). Paradójicamente lo que unas décadas atrás fue mirado con recelo por el articulista de La Estrella Nacional — citado al inicio de este trabajo - es tenido por una gran oportunidad por parte de Pérez: la afición a las novelas. La defensa del género queda establecida; Pérez pasa al balance y concluye que hay pocas "novelas nacionales" en el ámbito suramericano (Pérez, 1858c: 93). Tal vez uno de los aspectos más interesante de este artículo de Felipe Pérez sea su reacción ante la crítica que recibió su novela Huayna Capac. El tono de la reflexión permite entrever un deseo de proponerse como estandarte, o modelo, de la novela histórica nacional. ${ }^{21}$ Reitera, al final del capítulo, su compromiso con la novela histórica, cuya senda "lo conduce [al escritor] a hacer conocer los pueblos, las familias i los personajes de que se ocupa, sus trajes, sus usos, costumbres, idioma, preocupaciones, estado de civilización" (Pérez, 1858c: 95). ${ }^{22}$

${ }^{21}$ Pérez, incluso, sigue el programa literario que defiende. Es un fecundo novelista histórico, autor de obras como: Huayna Capac (1856), Atahuallpa (1856), Los Pizarros (1857), Jilma (1858), Los jigantes (1875).

${ }^{22}$ Pérez insiste en la novela como vía para narrar la historia y emprender disertaciones filosóficas, de allí que atraiga como modelos a Sue, Dumas, Victor Hugo, Scribe y Bulwer (Pérez, 1858c: 85). 
El concepto "literatura nacional" como es construido por los articulistas vendría a cubrir una producción específica. Así, no todo lo escrito en suelo neogranadino o por autores neogranadinos sería literatura nacional. Esta literatura, según los textos programáticos, debe adoptar rasgos narrativos, de ahí la importancia concedida a géneros como la novela y el romance, y debe abordar unos temas concretos: gesta independentista, el paisaje, los prohombres, las costumbres: "Hoy se pide algo más a los novelistas que un simple cuento. Hoy se les pide historia, costumbres, y hasta doctrina" (Pérez, 1858c: 86).

\section{La literatura nacional: ¿entre el neoclasicismo y el romanticismo? A manera de conclusión}

El análisis de los artículos periodísticos revela un recepción parcial del romanticismo entre los letrados hispanoamericanos, para nuestro caso neogranadinos. Durante las primeras décadas del siglo XIX los autores se movieron entre ambas aguas: las del neoclasicismo y las del romanticismo (Oviedo, 2012). Incluso a mediados del siglo XIX Boileau goza de aceptación. La traducción de su obra se divulga en La Bagatela en 1852 y una figura como Felipe Pérez afirma en 1858 que: "El soplo poderoso de Boileau había sido bastante para hacer desaparecer las tontunas maravillosas de los escritores de Europa hasta el reinado de los últimos Luises en Francia" (Pérez, 1858c: 86). Es posible evidenciar la tensión que se vive en ese entonces en la Nueva Granada específicamente - seguramente la revisión de este fenómeno en otros países conlleve a similaresobservaciones- y que queda plasmada en los periódicos: ampararse en el neoclasicismo, con su preocupación didáctica y su prescriptiva, o trasegar los terrenos del romanticismo, con su libertad en la creación. En la Nueva Granada, lo leemos en los artículos, se rechaza todo tipo de efusión romántica individualista y alejada de la norma; pero al mismo tiempo se da un afán por proponer unos lineamientos que guíen los motivos, formas y función de la literatura adoptados por los escritores. Parecería contradictorio disponer una prescriptiva, una serie de "normas" a seguir, a una literatura fruto de una situación sociopolítica inspirada en ideales nacionalistas románticos que apelan a la libertad. Pero es así. Ello tiene que ver con las características que asume el romanticismo en tierras americanas. La cuestión primordial en el contexto neogranadino no es proponer una defensa a ultranza de una u otra tendencia estética sino instituir un fondo literario nacional que cumpliera una serie de requisitos, claramente expresados por los articulistas, y cuya recolección nos permite deducir el modelo de literatura nacional propuesto. Por ello no cualquier obra publicada por un autor neogranadino es considerada como parte del fondo literario nacional; las efusiones líricas sentimentales y con elementos góticos, fruto de la imitación al romanticismo individualista europeo, tan de moda entre los "versificadores" del momento, no pueden constituir una literatura de cuño nacional. Si algo queda claro después de leer los artículos periodísticos que se ocupan del estado y proyección de las letras neogranadinos es que para ser considerada nacional una obra literaria ha 
de cumplir una serie de rasgos, cumplir un suerte de prescriptiva que reúnen tanto elementos neoclásicos como románticos.

En primera instancia nos atrevemos a afirmar que el ánimo programático en sí es una tendencia de sesgo neoclásico, en el sentido en que se prescribe cómo ha de ser el fondo literario nacional y se rechazan de tajo aquellas manifestaciones que se alejan del modelo en construcción. La forma narrativa se privilegia en los textos de carácter programático. Bien sea a manera de romance o de novela histórica, la narración es la forma adecuada para las temáticas prescritas como pertinentes. Se encarga tanto para el caso de la novela como del romance que la obra deleite y a la vez forme al lector; este principio tiene profundas raíces en Horacio. Es posible proponer la inclinación por la forma novelesca como una ruptura con el credo neoclásico. Ya en el marco de la Ilustración la novela genera suspicacia pues no era posible encasillarla en la poética neoclásica, sin embargo se dan casos de novelas donde se respeta el precepto neoclásico de educar deleitando (Monguió, 1996: 115). De esta manera, un género aplaudido por el romanticismo, y que genera resquemores, puede llegar no solo a ser aceptado sino además privilegiado.

Así como para la forma, se propone una preceptiva para los temas que atiende a influencias románticas. Se recomienda a los autores acudir a la historia, al pasado heroico, al paisaje circundante, a los tipos sociales, en este sentido la preceptiva retoma elementos del romanticismo alemán: "La estética de los románticos subrayó la importancia de lo autóctono en el arte" (Krumpel, 2001: 47). El romanticismo "byronesco" se critica, en suma, por individualista, mientras que el romanticismo ligado a la historia se exalta por ser una manifestación útil a la idea de literatura nacional que se está forjando, en tanto permite construir un discurso sobre el progreso y fundamentar un proyecto civilizatorio.

Las ideas expuestas por los articulistas estudiados revelan un eje común con los discursos de cuño liberal a propósito de un arte socialista que florece en otras zonas de Hispanoamérica. Alberdi y Sarmiento, por ejemplo, defienden un arte a favor del progreso, de la civilización (Sasso, 1995). Dice Sasso: "Y si miramos un poco más de cerca, pronto advertiremos que esa elocuencia prosigue, sin visible ruptura, una línea intelectual y afectiva enraizada en la cultura renacentista y neoclásica $[. .$.$] y$ pudo así seguir nutriendo [...] el gesto discursivo de las generaciones subsiguientes" (1995: 86). Pese a que en los periódicos estudiados no se incluyen textos de los intelectuales que asociamos al núcleo intelectual asentado en Chile (Sarmiento, Alberdi, Bello), sí se encuentran algunas referencias al mismo. Felipe Pérez, en "De la novela", destaca la actividad y solidez del movimiento literario en Argentina y Chile, a la vez que señala los problemas de divulgación de sus obras en tierras neogranadinas (1858: 93); en "Literatura suramericana" reconoce a Bello 
- figura fundamental de este núcleo-, junto a Heredia y Olmedo, ${ }^{23}$ como prueba de los alcances de la literatura americana (1858: 54). Pese a las precarias condiciones de divulgación señaladas por Pérez, es evidente que en los periódicos neogranadinos surgen cuestiones sobre la función de la literatura cercanas a las que se discuten en el Sur. Se trata, indudablemente, es una preocupación de carácter continental, pues en Hispanoamérica estaba pendiente fundar las naciones, fundar las literaturas, las narrativas y los discursos cohesionadores que expresaran la nueva realidad sociohistórica a la cual se estaban enfrentando (Dávila, 2003: 61). De lo anterior se comprende que las temáticas señaladas como pertinentes para un fondo literario nacional neogranadino coincidan con las propuestas en otros países del Cono Sur; en su discurso liberal sobre la literatura, Lastarria, por ejemplo, propone como temas para el fondo literario nacional acudir a los atributos naturales del territorio, describir las costumbres, recordar los hechos heroicos, interrogar las necesidades sociales del pueblo (Dávila, 2003: 66).

La adopción de elementos de repertorios foráneos para el propio programa literario - vía traducción, reproducción de obras de carácter reflexivo y reseñas de obras literarias de autores extranjeros - atiende en buena parte a condicionamientos políticos e ideológicos, más que a criterios estéticos (Dávila, 2003: 56). En esta lógica podría entenderse la crítica mordaz en contra de los imitadores del romanticismo sentimental y gótico, quienes representarían la adopción del romanticismo en su esfera más individualista.

Resultan comprensible entonces las afirmaciones contenidas en el prólogo a Manuela, escrito por José María Vergara y Vergara y reproducido en el primer número de El Mosaico. En este texto Vergara y Vergara, el primer historiador de la literatura colombiana, uno de los hombres más preocupados en su momento por recopilar y estudiar la producción de autores nacionales, asevera que el relato de Eugenio Díaz es en rigor la primera novela nacional (aunque no desconoce como antecedentes las obras de Ángel Gaitán y Pérez): "[Manuela es una] novela eminentemente nacional i provechosa" (Vergara, 1859: 8). El prologuista y redactor de El Mosaico justifica sus afirmaciones en aspectos como la inscripción de la obra en el género novelesco, los motivos cercanos a los tipos y costumbres nacionales y su potencial formador. Vergara, además, destaca de la obra "la orijinalidad, un tino esquisito, una observación juiciosa i una apreciación rápida y feliz" (Vergara, 1859: 8), rasgos que superpone a los posibles problemas de estilo, que también resultan evidentes y que no obvia. Manuela cumple con buena parte de las características de una obra digna de conformar el fondo literario nacional; se ajusta a los rasgos

${ }^{23}$ Heredia, Olmedo, Bello se cuentan entre quienes anuncian la cercanía de la corriente romántica en América (Carilla, 1967: 52). La admiración que Pérez expresa hacia estos autores implica una cercanía con sus apuestas estéticas, la cual se revela en sus propuestas acerca de la novela. 
defendidos en los textos programáticos, $\mathrm{y}$, muy importante, deja radicalmente de lado todo atisbo de "romanticismo byronesco".

\section{BIBLIOGRAFÍA}

\section{Fuentes primarias}

BOILEAU, Nicolás.

1852 "Poesía", José María Salazar (traductor). La Bagatela, n 2, 1852, s.p.

CAICEDo Rojas, José.

1858 "El romance. Necesidad de que los poetas suramericanos cultiven este género", Biblioteca de Señoritas, $\mathrm{n}^{\circ}$ 6, 1858, p.45.

GIL Y ZÁRATE, Antonio.

1849 "Diferencias esenciales entre la literatura antigua y la moderna. Clasicismo-romanticismo", El Museo, tomo 1, n 5, pp. 65-71.

PÉREZ, Felipe.

$1858^{\mathrm{a}}$ "Literatura Suramericana", Biblioteca de Señoritas, n 7, 1858, p. 53.

1858b “¿Quién tiene la culpa?”, Biblioteca de Señoritas, n ${ }^{\circ}$, 1858, pp. 61-62.

$1858 \mathrm{c}$ "De la novela", Biblioteca de señoritas, $1858, \mathrm{n}^{\circ} 11$ y 12, pp. 85-86 y 93-95.

ROJAS GARRIDO, José María.

1846 "Una noche romántica y un día clásico", El Albor Literario, s.n., 1846, pp. 3-6.

STAËL, Madame de.

1838 "Influjo de la literatura sobre la libertad", El Argos, trim. 5, n 57, 1838, pp. 237-238.

S.D.

1836 "Novelas", La Estrella Nacional, trim. I, n 1, 1836, pp. 1-2.

1848 "Bellas letras", El Cachifo. Periódico literario, trim. 1, n 1, 1848, pp. 2-4.

1849b "Llanto y melancolía", n 1, El Museo, 1849, p. 4-6.

1849 c "Poesía americana", El Neogranadino, n 23, 1849, pp. 3-4.

1849d "Poesía nacional”, El Neogranadino, n 30, 1849, p. 49.

1851 "Literatura nacional", La Reforma. Periódico de la escuela republicana, trim. $1, \mathrm{n}^{\circ} 10,1851$, s.p.

T. G. U.

1855 "Literatura nacional”, El Tiempo, n 52, 1855, s.p.

1849 "Nuestra literatura", Ensayo Literario, n 6, 1849, pp. 1-2. 
VERgARA Y VERGARA, José María.

1859 "Manuela. Novela original de Eugenio Díaz Castro", El Mosaico, $\mathrm{n}^{\circ} 1$ y 2,1859 , pp. 8 y 16.

\section{Fuentes secundarias}

BELLO, Andrés.

1993 “Alocución a la poesía”. José Ramos (ed.). Antología esencial.

Caracas: Biblioteca Ayacucho, pp. 4-24.

CARILla, Emilio.

1967 El romanticismo en Hispanoamérica. Madrid: Gredos.

DÁVILA, Luis Ricardo.

2003 "La expresión literaria de la nación hispanoamericana", Revista chilena de literatura, ${ }^{\circ}$ 63, 2003, pp. 53-71.

DONOSO CORTÉS, Juan.

1854 Obras de Don Juan Donoso Cortés, Gavino Tejado (ed.). Madrid: Imprenta de Tejado. Disponible en:

https://archive.org/details/obrasdedonjuand00tejagoog. Consultado el 20 de febrero de 2013.

EVEN-ZOHAR, Itamar.

2011a "El sistema literario". Polisistemas de cultura. Tel Aviv:

Universidad de Tel Aviv, pp. 29-48. Disponible en:

http://www.tau.ac.il/ itamarez/works/papers/trabajos/polisistemas de_cultura2007.pdf Consultado: 22 de abril de 2013.

2011 b "La posición de la literatura traducida en el polisistema literario". Polisistemas de cultura. Tel Aviv: Universidad de Tel Aviv, pp. 8897. Disponible en:

http://www.tau.ac.il/ itamarez/works/papers/trabajos/polisistemas

GIL Y ZÁRATE, Antonio. de_cultura2007.pdf Consultado el 20 de octubre de 2013.

1861 Principios generales de retórica y poética. Primera parte del

Manual de literatura. Madrid: Imprenta de Gaspar y Roig.

Disponible en: https://archive.org/details/principiosgenera00gily.

Consultado el 15 de febrero de 2014

KRUMPEL, Heinz.

2001 "Ilustración, romanticismo y utopía en el siglo XIX. La recepción de la filosofía clásica alemana en el contexto intercultural de Latinoamérica", Signos históricos, nº 6 , 2001, pp. 25-91. Disponible en:

http://www.juridicas.unam.mx/publica/librev/rev/signos/cont/6/pr/p r2.pdf Consultado el 20 de febrero de 2014.

MELO, Jorge Orlando. 
2008 "Las revistas literarias en Colombia e Hispanoamérica: una aproximación a su historia". Colombia es un tema. Portal web. Disponible en: http://www.jorgeorlandomelo.com/bajar/revistas_suplementos_liter arios.pdf. Consultado el 25 de febrero de 2014.

MONGUIÓ, Luis.

1996 "La poética neoclásica en la América Hispana", Revista de Crítica Literaria Latinoamericana, año XXII, n 43-44, 1996, pp. 103-117. OviEDo, José Miguel.

2012 Historia de la literatura hispanoamericana. 1. De los orígenes a la emancipación. Madrid: Alianza.

SASSO, Javier.

1995 "Romanticismo y política en América Latina. Una reconsideración”. Esplendores y miserias del siglo XIX. Cultura y sociedad en América Latina. Caracas: Monte Ávila, pp. 73-90.

STAËL, Madame de.

1800 De la littérature considérée dans ses rapports avec les institutions sociales. Paris: Bibliothèque-Charpentier. Disponible en:

https://archive.org/details/delalittrature00sta Consultado el 15 de febrero de 2014

VALLEJO, Olga.

2012 "El arte poética de Nicolás Boileau en la traducción de José María Salazar (1810)". Biblioteca de traducciones hispanoamericanas. Portal Web. Alicante: Biblioteca Virtual Miguel de Cervantes. Disponible en: http://www.cervantesvirtual.com/obra/el-artepoetica-de-nicolas-boileau-en-la-traduccion-de-jose-maria-salazar-

VIÑAS, David. 1810/ Consultado el 5 de febrero de 2014.

2002 Historia de la crítica literaria. Barcelona: Ariel. ZEA, Leopoldo.

1976 El pensamiento Latinoamericano. Barcelona: Ariel. 